\title{
COMPARISON OF CONVENTIONAL AND HYBRID CARS EXPLOITATION COSTS
}

\author{
Saugirdas Pukalskas ${ }^{1}$, Alfredas Rimkus², Mindaugas Melaika ${ }^{3}$, Robertas Pečeliūnas ${ }^{4}$ \\ 1 Vilnius Gediminas Technical University, Faculty of Transport Engineering, J. Basanavičiaus Str. 28, 03224 \\ Vilnius, Lithuania, e-mail: saugirdas.pukalskas@vgtu.It, alfredas.rimkus@vgtu.lt, mindaugas.melaika@vgtu.It, \\ robertas.peceliunas@vgtu.It
}

Received: 2018.01 .15 Accepted: 2018.02.01 Published: 2018.03.01

\begin{abstract}
The paper analyzes three different, but similar class cars, two of them with conventional spark ignition (SI) engines, and one - hybrid (SI + electricity). Statistics of fuel consumption and mileage of several years are presented and analyzed, fuel price changes and provided exploitation costs. The analysis shows that in countries where are no privileges for the acquisition of hybrid cars or for operation (less parking or tolls, insurance or technical inspection price), the payback is hardly possible, because the hybrid car's price is about 2 times higher than that of a normal car, and fuel costs are reduced merely by about $20 \%$. The results of the analysis show that payback of the hybrid car (at current fuel prices), in the best case possible after 0,73 million kilometers. Within annual mileage an average of 25 thousands $\mathrm{km}$, the hybrid car will payback after 30 years!
\end{abstract}

Keywords: hybrid car, exploitation costs, fuel consumption

\section{INTRODUCTION}

The reduction of oil sources, the increase of environment pollution and the intensification of climate change have the whole world looking for alternative fossil energy sources for more efficient usage. People are worried that, due to the climate becoming warmer and the glaciers melting, the rising ocean water will flood huge land territories, therefore, in the United Nations Climate Change Conference in 2015 in Paris it was decided to take immediate measures to reduce the exhaust of $\mathrm{CO}_{2}$ preventing the global warming [1].

Every one is obliged to contribute to reducing the global warming, therefore, the most simple way to do that is to make our trips more ecological. During the last several years vehicle manufacturers payed a lot of attention to new mechanisms and systems for conventional engines - downsizing ( small capacity engines), cylinder on demand (e.g. half of cylinders are shut off at part load working regemes), integrated starters generators,
$48 \mathrm{~V}$ systems and electrification. However, some of the engineering solutions did not fulfil the expectations. For example, according to some great producers there is no need to do further downsizing for three cylinder engines (capacity lower than 1 liter) or four cylinder engines (capacity lower than 1.5 liter). The real-world emission tests showed the differences between NEDC and real-world where real-world consumptions were particularly larger in downsized engines. It was mentioned that downsizing can have a negative effect on emissions, particularly when a tiny engine drives a heavy car and is running on turbo all the time [2]. Therefore, different solutions have to be applied in order to meet high EURO standards. In this case, instead of a conventional cars, it is possible to use ecologic hybrid vehicles, which have been manufactured and offered for purchasing by many car manufacturers for more than a year [3].

Hybrid vehicle is the most complex vehicle of all known vehicle types (comparing the conventional, electric and hybrid), because it has not 
one, like the otheres, but two energy converters (engines) and two energy saving systems (fuel tank and electricity accumulator battery) [4]. And the functioning of these systems has to be in perfect harmony so that the vehicle would move smoothly and would not cause inconveniences to the driver, passengers or other road users [5]. That is why complex technologies used in them justify the cost of the vehicle - in most cases the cost of the hybrid vehicle is two times bigger than that of a conventional vehicle and matches the cost of the electic vehicle.

However, the benefit of the hybrid vehicle has not been giving any doubt to anyone recently. Researchers Pitanuwat and Sripakagorn [6] in their research have determined that hybrid vehicle is the most beneficial under the most difficult traffic conditions, i.e., where there are frequent, intense accelarations and breakings. When moving at a higher velocity and when the acceleration is less changing the difference between the fuel consumption of the conventional and the hybrid vehicle makes up only $21 \ldots .26 \%$. While at the same time, the hybrid vehicle under difficult city regime consumes $47 . . .56 \%$ less fuel than a conventional vehicle.

Dutch scientists carried out comprehensive research and the results showed that hybrid cars may reduce fuel consumption by $34 . . .47 \%$ compared to conventional cars and reduce well-to-wheels green house gas emissions to $89 \ldots 103 \mathrm{~g} \mathrm{CO}_{2} \mathrm{~km}^{-1}$. However, hybrid cars currently cost $5000 \ldots 10000$ EUR more than conventional cars [7].

Better results, e.g. less fuel consumption, are achievable with chargable hybrid vehicle. American and Chinese research revealed that real fuel consumption of a chargable vehicle is from 3.03 to $4.391 / 100 \mathrm{~km}$ [8].

Japanese scientists [9] analyzed the used car market data in Japan, and examined whether a difference exists between hybrid vehicle and conventional (petrol) vehicle owners in terms of vehicle usage. The analysis of vehicle traveling data reveals that drivers with high travel demand switched their vehicles from conventional vehicle to hybrid vehicle in the hybrid transition period. The analysis also shows that hybrid vehicle owners drive a longer distance annually than conventional vehicle owners. Despite the higher mileage, $\mathrm{CO}_{2}$ emissions from hybrid vehicles are lower than that from conventional vehicles. Therefore, hybrid vehicles can contribute to the global warming mitigation, even if hybrid vehicles induce the rebound effect. Also they found that hybrid vehicle owners spend roughly the same amount of money on their vehicles annually as conventional vehicle owners. However, hybrid vehicle owners spend less money to travel $100 \mathrm{~km}$ than conventional vehicle owners. Hence, the average hybrid vehicle owner cannot recover the initial higher cost when they purchase a hybrid vehicle.

The works done by some researchers $[10,11]$ reveal that there are big differences between the actual fuel consumption and the consumption declared by the car manufacturers. In some cases these differences reach even $50 \%$. It is determined by researches that this difference can be influenced by various factors, such as frequent use of $\mathrm{A} / \mathrm{C}$ systems, electric auxiliarities or difficult traffic conditions, however, the differences are also influenced by the lack of the research tests.

Other scientists from China [12] investigated city buses using portable emission measurement system and found that hybrid buses reduced fuel consumption with electric power generated from regenerative braking. Because diesel engine seldom charges the battery, the engine loads of hybrid buses were lower than those from diesel buses. Therefore, the BSFCs for hybrid buses were higher than those for diesel buses.

Also they found another very important thing, for hybrid buses, although the engine-out $\mathrm{NO}_{\mathrm{x}}$ emissions were lower than in diesel buses, the lower engine load reduced the exhaust temperature, which led to lower urea injection ratio and higher tailpipe $\mathrm{NO}_{\mathrm{x}}$ emissions for hybrid buses

Regardless the comprehensive researches, the main disadvantage of hybrid buses is that, the displacement of the engines was the same. However, the best hybridization effect of the vehicles, as it is determined in the FP7 project "Clean European Rail-Diesel" [13], manifests when the displacement and power of the internal combustion engine is reduced, and the thrust of the vehicle remains the same or similar because the electric engine helps to gather momentum. The main saving of the fuel in hybrid vehicle appears due to the reduced displacement and power of the internal combustion engine.

Antti Lajunen from Aalto university analyzed fuel economy for heavy vehicle combinations [14]. The simulation results clearly indicated that the payload specific fuel consumption could be significantly reduced by using heavier combinations. The impact of the operating cycle was strongly emphasized in this study, as the results showed that the fuel economy of a heavy vehicle combination is heavily impacted by the amount of hill climbing in the operating route.

Zahabi and other scientists from Canada investigated the impact of different factors (operating 
link-level speeds, road environment, temperature, cold-starts, eco-driving, etc.) on fuel efficiency of popular hybrid electric vehicles in real world conditions and comparing their performance with respect to standard gasoline vehicles [15].

The results showed that an HEV consumes less gasoline in spring compared to winter time due to the improved performance of its batteries at higher ambient temperatures. The winter season and in particular low temperatures have a significant negative impact on HEVs. In this study, cold months or low temperatures increase fuel consumption of hybrid vehicles (about a 27\% increase in fuel consumption rate compared to spring).

Scientists from Canada and Slovakia observed that HEV are $26-28 \%$ more fuel efficient than gasoline vehicles $[15,16]$. However, the fuel efficiency of HEVs is more sensitive to changes in ambient temperature. For instance, if the temperature goes from $8^{\circ} \mathrm{C}$ to $16^{\circ} \mathrm{C}$, the fuel consumption rate of HEV sedans reduces by $3 \%$ while for conventional vehicles, this reduction is only $1 \%$.

Scientists from China performed an energy, environmental and economic assessment of the penetration of HEVs into the taxi fleet in Macao. The results showed that although HEVs have higher vehicle cost, their better energy economy can save annual fuel costs relative to diesel cars. This could provide a payback period of only $2-3$ years, much shorter than the typical in-service duration of diesel taxis in Macao (8 years) [17].

Scientists from Slovenia [18], who have done a cost benefit analysis of various buses (diesel, natural gas and hybrid) say that the hybrid bus will not reach the usual exploitation costs of a diesel bus for almost 20 years.
Tank to Wheel analysis of Italian scientists [19] showed that a hybrid car consumes about $20 \%$ less energy and releases less $\mathrm{NO}_{x}, \mathrm{PM}, \mathrm{SO}_{\mathrm{x}}$ emissions than a conventional car.

The hybrid technology is now particularly favoured for heavy-duty vehicles such as city-buses and leads to $20-30 \%$ reduction in both energy consumption and associated emissions. For personal cars, the deployment of hybrid drive trains is a logical way to reduce fuel consumption and $\mathrm{CO}_{2}$ emissions [20].

The purpose of this article is to analyze the real fuel consumption of three different cars, running for several consecutive years, and explore the potential payback of a hybrid vehicle.

\section{INVESTIGATION METHOD}

Two conventional cars (Toyota Corolla, Audi A3) and one hybrid car (Toyota Prius) were tested in this study. The details of these cars sumarized in Table 1.

Reseach was carried out with three vehicles at different time periods. All vehicles were different age and run. Toyota Corolla was 6 years old, Toyota Prius 1 year old at the beginning of investigation and Audi $A 3$ was totally new from the investigation beginning. The research was carried out in such time periods: Toyota Corolla - from 2003 year beginning to middle of 2008; Toyota Prius - from 2008 middle to 2017 middle; Audi A3 - from 2012 beginnning to 2017 middle.

The vehicles were exploited during different time periods, however, the same research method was applied. During each filling of the fuel tank, the full tank is filled and the driven mileage is written down. The amount of the fuel that was

Table 1. Technical data of the tested cars

\begin{tabular}{|l|c|c|c|}
\hline \multicolumn{1}{|c|}{ Parameter } & Toyota Corolla & Toyota Prius & Audi A3 \\
\hline Production year & 1994 & 2007 & 2011 \\
\hline Engine type & spark ignition & spark ignition & spark ignition \\
\hline Engine displacement, $\mathrm{cm}^{3}$ & 1332 & 1497 & 1197 \\
\hline Engine max. power, $\mathrm{kW}\left(\mathrm{min}^{-1}\right)$ & $65(6000)$ & $57(5000)$ & $77(5000)$ \\
\hline Max. torque, Nm $\left(\mathrm{min}^{-1}\right)$ & $124(5000)$ & $111(4200)$ & $175(1550 \ldots 4100)$ \\
\hline Fuel $(\mathrm{ON})$ & $95 \mathrm{RON}$ & $95 \mathrm{RON}$ & $95 \mathrm{RON}$ \\
\hline Acceleration $0-100 \mathrm{~km} / \mathrm{h}, \mathrm{s}$ & 11,5 & 10,9 & 10,5 \\
\hline Motor type & - & Synchronous, AC & - \\
\hline Motor max. power, $\mathrm{kW}\left(\mathrm{min}^{-1}\right)$ & - & $50(1200 \ldots 1540)$ & - \\
\hline Motor max. torque, $\mathrm{Nm}\left(\mathrm{min}^{-1}\right)$ & - & $400(0 \ldots 1200)$ & - \\
\hline Rated voltage, $\mathrm{V}$ & - & AC 500 & - \\
\hline
\end{tabular}


filled shows how much fuel was consumed to drive a given mileage. After the filling the odometer is set back to zero and it is driven like that until the next fuel filling.

It can be assumed that such a method is not accurate enough for scientific research, however, all vehicles' odometers were checked periodically (especially while changing the tyres) and if necessary, data corrections were applied. Naturally, nowadays new vehicle's fuel tanks can not be filled up fully because the gathering systems for petrol vapour can be damaged. Therefore, while filling until the petrol pistol gets "tiggered", the instantaneous errors appear because of different fuel filling level. However, such an error is eliminated and it does not make a big influence during the time and during the record of average consumptions.

The purchase cost and the fuel consumption were evaluated during the research. It was deemed that the technical maintenance and the repair costs of the vehicle will be equal for each vehicle.

\section{RESULTS AND DISCUSSION}

In Figure 1 the changes of petrol prices in Lithuania and crude oil prices in the world in period of 2007-2017 are presented. This picture shows that the fuel cost in Lithuania from 2002 to 2012 constantly and rapidly increased until the middle of the year 2008. The global economic crisis that started in 2008 affected not only the oil cost but also the fuel costs in Lithuania, consequently it rapidly decreased. However, after less than two years, the fuel cost in Lithuania reached the level of prior crisis again and it kept further increasing even though the oil costs were never as high as they were before the economic crisis.

In the end of 2014, due to various global geopolitical events, when the oil costs started to decrease again, the fuel cost in Lithuania also decreased but after the introduction of the euro in Lithuania on January 1st, 2015, the cost started to increase again. This phenomenon, when the prices start to inrease after introducing the euro was felt in many countries and not only in the area of fuel and other energetic resources. Even though the global oil costs currently have decreased to a relatively low level (aprox. $50 \$ /$ barrel), the fuel costs in Lithuania remain relatively high, almost the same as during the period of prior crisis.

In Figure 2 we can see the actual fuel consumption of the three vehicles that took part in the research. The blue curve marks the fuel consumption of Toyota Corolla, the red one - hybrid Toyota Prius, the green one - Audi A3. The graphs clearly show that the average fuel consumption of the hybrid vehicle is approximately 1.0...1.5 litres less than Toyota Corolla and approximately 1.5...2.0 litres less than Audi A3.

In the Figure 2 the consumption sesionality becomes very clear - the consumption in winter is much bigger than in summer. That can especially be said about the two Toyota vehicles. The fuel consumption of Toyota Corolla vehicle during the

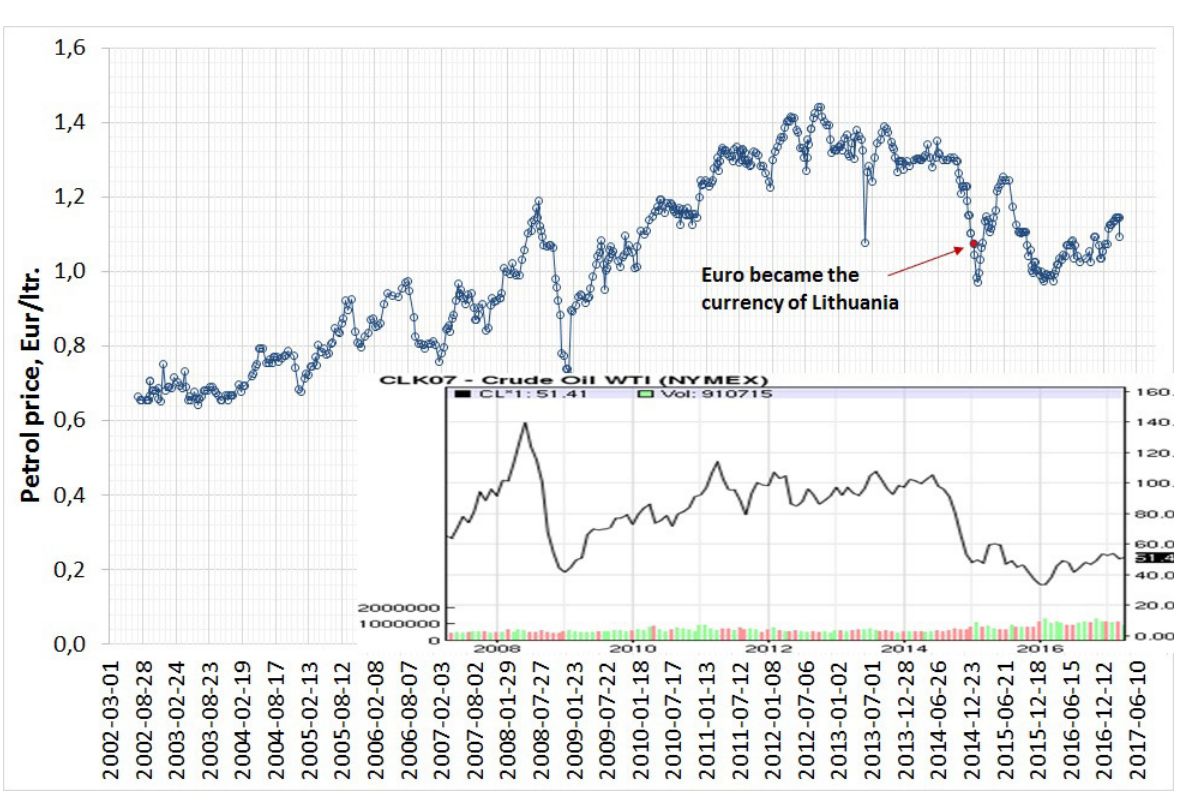

Fig. 1. The change of petrol prices in Lithuania in 2002-2017 and crude oil prices in 2007-2017 [21] 
warm season was about 5.5...6.5 1/100 km, and during the cold season it would increase to $8 \ldots 9$ $1 / 100 \mathrm{~km}$. The most interesting is the fact that even though the fuel consumption of the hybrid vehicle during the warm season would reach only 4.0...4.5 1/100 km, during the cold period, in some cases, it would reach more than that of the conventional vehicles - 10.0...10.5 1/100 km.

When exploiting this hybrid vehicle it was noticed that the fuel consumption drastically increases when it is especially cold and when driving short, up to a few kilometres, distances. It is thought that the capacity of the high-voltage battery of the vehicle, at very low temperatures, decreases and it has to be recharged, therefore, after driving short distances, the engine warms up and the baterry is charging, which requires additional energy.

While evaluating the change of the fuel consumption of the researched vehicles, the average day mileage is very important, which shows the nature of the exploitation of the vehicle (Fig. 3). When exploiting the vehicle in short distances the fuel consumption will always be bigger than that of the vehicle which is exploited in long distances. The main reason for this is deemed to be the operating of the engine at higher speeds during the warming up, or to say more accurately - with a bigger amount of flammable mixture. In the case of the hybrid car, during the cold season and warming up, the vehicle also consumes more fuel because the energy in the battery is lost due to the

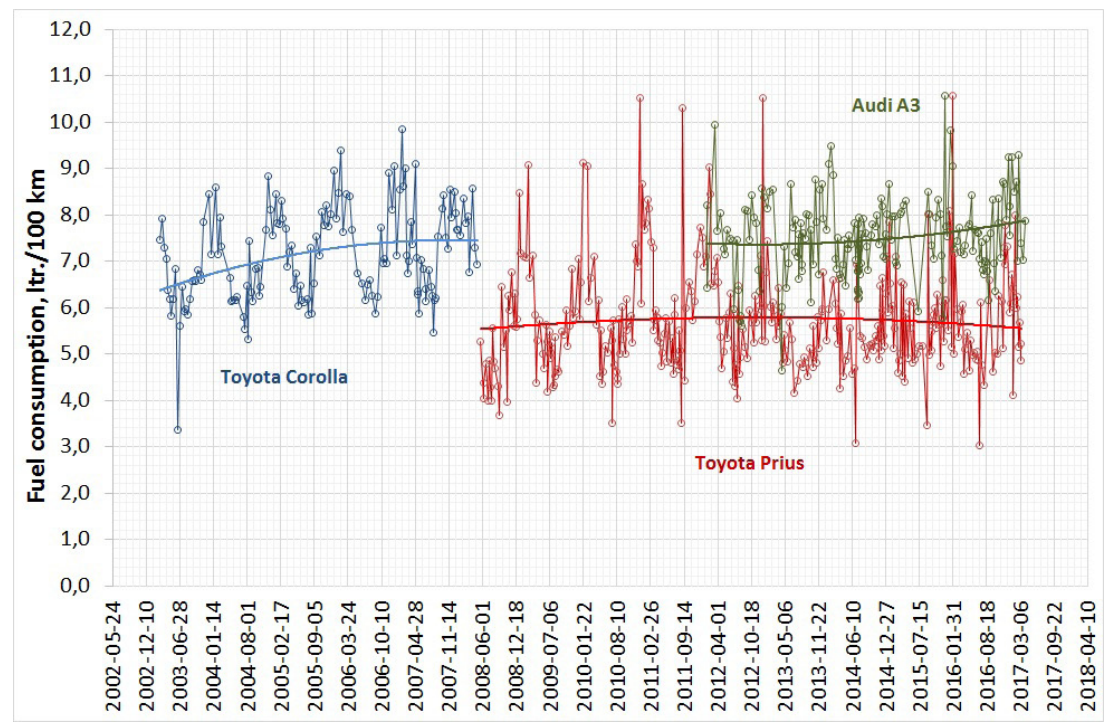

Fig. 2. The fuel consumption of three different cars

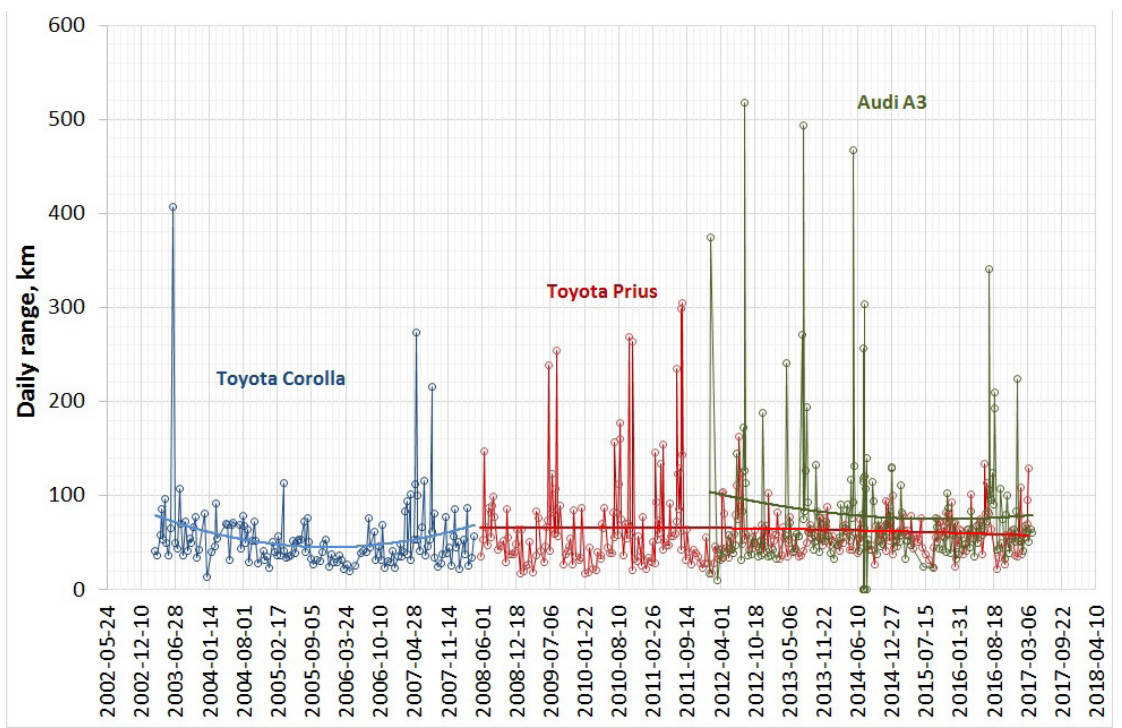

Fig. 3. Daily range of three different cars 
cold, therefore, after starting the car it needs to be recharged too. After driving longer distances, $20 \mathrm{~km}$ and more, this initial stage of the engine warming up does not create a big impact on the increase of the fuel consumption.

Therefore, in order to speak about the comparison of the exploitation costs of these three vehicles, firstly, it is important to evaluate the purchase cost of these cars. The costs of new such models (or similar ones) in Lithuania during the second quarter of the year 2017 are as follows: Toyota Corolla - $13940 €$, Toyota Prius $-25000 €$, Audi A3 - $24000 €$.

From the original comparison, it can already be seen that the exploitation costs of Audi A3 will be the largest because the initial cost is very similar to that of the hybrid Toyota Prius but the fuel consumption is significantly larger than the latter.

Figure 4 clearly illustrates that the most expensive exploitation is of Audi A3, and the cheapest one to $730000 \mathrm{~km}$ - Toyota Corolla. The operational expenditures for fuel of the hybrid Toyota Prius, even though the cost is similar to that of Audi A3, do not increase that rapidly as those of Audi A3 ar Toyota Corolla. However, the significantly lower initial Toyota Corolla price allows it to be the "leader" even up to $730000 \mathrm{~km}$.

Therefore, this research lets you understand that the payback of the hybrid vehicle, comparing it to a vehicle of a similar configuration and of similar size and of the same manufacturer, is hardly possible because there are any stimulative privileges for the purchase and use of such cars in Lithuania, like possibility to drive in the bus lines (like for electric cars) or cheaper parking fee. In this case, the total cost of ownership for hybrid vehicle gets equal with conventional vehicle just after $29.2 \ldots 36.5$ years or after $730000 \mathrm{~km}$ mileage, if it is driven average $20 \ldots 25$ thousand $\mathrm{km}$ per year [8]. It is clear that no modern vehicle could reach such age because not only it technically wears out but also gets old morally.

According to Dutch scientists [7] the higher purchase cost of hybrid cars means they are financially interesting for taxi and others drivers who drive more than $80,000 \mathrm{~km}$ per year. For these drivers, the hybrid cars would the most attractive option, even without tax incentives. Including the Dutch tax incentives, the total cost of ownership of a hybrid car is currently lower than that of a diesel car even when driving around $20,000 \mathrm{~km}$ per year.

What is more, there is no pollution taxes in Lithuania for the cars which could depend on vehicle type: big or small, old or new. The road taxes are included into the fuel excise. Insurance companies mainly calculate the insurance fee depending on internal combustion engine displacement, therefore, marginally lower change is applied to the hybrid vehicles because of smaller engines' capacity. However, much lower insurance deposits could contribute for the less enviromental pollution and at the same time improving humanity health which is also associated with lower insurance payoff.

The market of ecologic vehicles in Lithuania and other countries, where similar policy is applied, is influenced negatively due to the abovementioned reasons.

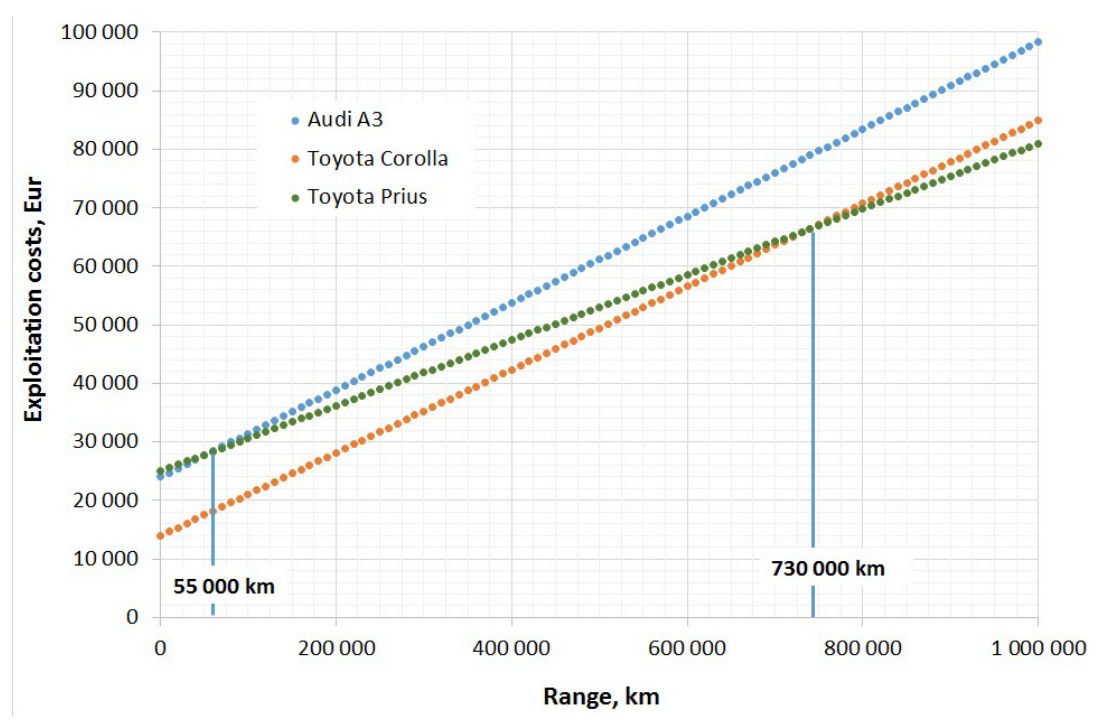

Fig. 4. Exploitation costs of three different cars 


\section{CONCLUSIONS}

After doing a comparison of exploitation costs (the purchase cost and the expenditures for fuel) of three different vehicles Audi A3, Toyota Corolla and hybrid Toyota Prius it has been determined that the payback of the hybrid vehicle, comparing it to a vehicle of similar configuration and of similar size and of the same manufacturer, is hardly possible because after driving average $20 \ldots 25$ thousand $\mathrm{km}$ per year, you would need $29.2 . .36 .5$ years to complete $730000 \mathrm{~km}$ distance.

It is clear that without the state support for the ecological hybrid vehicles, their payback is hardly possible, or after evaluating big mileages it can be stated that it is completely impossible.

\section{REFERENCES}

1. http://unfccc.int/meetings/paris_nov_2015/meeting/8926.php

2. Taylor M. Who killed downsizing? Engine Technology International, March, 2017, 44-50.

3. Kapustin A., Rakov V. Methodology to Evaluate the Impact of Hybrid Cars Engine Type on their Economic Efficiency and Environmental Safety. Transportation Research Procedia, 20, 2017, 247-253.

4. Regulation No 83 of the Economic Commission for Europe of the United Nations (UNECE) - Uniform provisions concerning the approval of vehicles with regard to the emission of pollutants according to engine fuel requirements [2015/1038] http://eur-lex.europa.eu/legal-content/EN/TXT/PD F/?uri=uriserv:OJ.L_.2015.172.01.0001.01.ENG

5. Raslavičius L., Keršys A., Makaras R. Management of hybrid powertrain dynamics and energy consumption for 2WD, 4WD, and HMMWV vehicles. Renewable and Sustainable Energy Reviews, 68, 2017, 380-396.

6. Pitanuwata S., Sripakagorn A. An Investigation of Fuel Economy Potential of Hybrid Vehicles under Real-World Driving Conditions in Bangkok. Energy Procedia, 79, 2015, 1046-1053.

7. Van Vliet O. P. R., Kruithof T., Turkenburg W. C., Faaij A. P. C. Techno-economic comparison of series hybrid, plug-in hybrid, fuel cell and regular cars. Journal of Power Sources, 195, 2010, 6570-6585.

8. He X., Wu Y., Zhang Sh., Tamor M. A., Wallington T. J., Shen W., Han W., Fu L., Hao J. Individual trip chain distributions for passenger cars: Implications for market acceptance of battery electric vehicles and energy consumption by plug-in hybrid electric vehicles. Applied Energy, 180, 2016, 650-660.
9. Iwata K., Matsumoto Sh. Use of hybrid vehicles in Japan: An analysis of used car market data. Transportation Research Part D, 46, 2016, 200-206.

10. Fontaras G., Zacharof N.-G., Ciuffo B. Fuel consumption and $\mathrm{CO} 2$ emissions from passenger cars in Europe - Laboratory versus real-world emissions. Progress in Energy and Combustion Science, 60, 2017, 97-131.

11. Barta D., Mruzek M., Kendra M., Kordos P., Krzywonos L. Using of non-conventional fuels in hybrid vehicle drives. Advances in science and technology research journal, 10, 2016, 240-247.

12. Guo J., Ge Y., Hao L., Tan J., Peng Z., Zhang Ch. Comparison of real-world fuel economy and emissions from parallel hybrid and conventional diesel buses fitted with selective catalytic reduction systems. Applied Energy, 159, 2015, 433-441.

13. Clean European Rail-Diesel. Deliverable 7.4.2: Energy storage technology comparative report. EC Contract No. FP7 - 234338. 2010. Available on internet: http://www.cleaner-d.eu/

14. Lajunen A. Fuel economy analysis of conventional and hybrid heavy vehicle combinations over realworld operating routes. Transportation Research Part D, 31, 2014, 70-84.

15. Zahabi S. A. H., Miranda-Moreno L., Barla P., Vincent B. Fuel economy of hybrid-electric versus conventional gasoline vehicles in real-world conditions: A case study of cold cities in Quebec, Canada. Transportation Research Part D, 32, 2014, 184-192.

16. Skrucany T., Harantova V., Kendra M., Barta D. Reducing energy consumption by passenger car with using of non-electrical hybrid drive technology. Advances in science and technology research journal, 11, 2017, 166-172.

17. Wu X., Zhang Sh., Wu Y., Li Z., Ke W., Fu L., Hao J. On-road measurement of gaseous emissions and fuel consumption for two hybrid electric vehicles in Macao. Atmospheric Pollution Research, 6, 2015, 858-866.

18. Gerbec M., Samuel R. O., Kontic D. Cost benefit analysis of three different urban bus drive systems using real driving data. Transportation Research Part D, 41, 2015, 433-444.

19. Torchio M. F., Santarelli M. G. Energy, environmental and economic comparison of different powertrain/fuel options using well-to-wheels assessment, energy and external costs - European market analysis. Energy, 35, 2010, 4156-4171.

20. Van Mierlo J., Maggetto G., Lataire Ph. Which energy source for road transport in the future? A comparison of battery, hybrid and fuel cell vehicles. Energy Conversion and Management, 47, 2006, 2748-2760.

21. http://www.nasdaq.com/markets/crude-oil.aspx 